University of Wollongong

Research Online

Faculty of Engineering and Information

Faculty of Engineering and Information

Sciences - Papers: Part A

Sciences

$1-1-2014$

\title{
Tensile fracture of ultrafine grained aluminum 6061 sheets by asymmetric cryorolling for microforming
}

\author{
Hailiang Yu \\ University of Wollongong, hailiang@uow.edu.au \\ A Kiet Tieu \\ University of Wollongong, ktieu@uow.edu.au \\ Cheng Lu \\ University of Wollongong, chenglu@uow.edu.au \\ Yanshan Lou \\ Swinburne University of Technology \\ Xianghua Liu \\ Northeastern University, liuxh@uow.edu.au
}

See next page for additional authors

Follow this and additional works at: https://ro.uow.edu.au/eispapers

Part of the Engineering Commons, and the Science and Technology Studies Commons

Research Online is the open access institutional repository for the University of Wollongong. For further information contact the UOW Library: research-pubs@uow.edu.au 


\title{
Tensile fracture of ultrafine grained aluminum 6061 sheets by asymmetric cryorolling for microforming
}

\author{
Abstract \\ The size effect on the mechanism of fracture in ultrafine grained sheets is an unsolved problem in \\ microforming. This paper describes a tensile test carried out to study the fracture behavior and the shear \\ fracture angles of both rolled and aged ultrafine grained aluminum 6061 sheets produced by asymmetric \\ cryorolling. A scanning electron microscope was used to observe the fracture surface. The finite element \\ method was used to simulate the tensile test using the uncoupled Cockcroft-Latham and Tresca criteria \\ and the coupled Gurson-Tvergaard-Needleman damage criterion. It was found that the shear fracture \\ angle decreases gradually from 90 degrees to 64 degrees with an increasing number of passes. The \\ results of simulations using the Gurson-Tvergaard-Needleman criterion show trends similar to the \\ experimental ones. The paper also presents a discussion on the fracture mechanism and the size effect \\ during the tensile test.

\section{Keywords} \\ fracture, aluminum, 6061, sheets, asymmetric, grained, cryorolling, microforming, ultrafine, tensile \\ Disciplines \\ Engineering | Science and Technology Studies

\section{Publication Details} \\ Yu, H., Tieu, K., Lu, C., Lou, Y., Liu, X., Godbole, A. and Kong, C. (2014). Tensile fracture of ultrafine grained \\ aluminum 6061 sheets by asymmetric cryorolling for microforming. International Journal of Damage \\ Mechanics, 23 (8), 1077-1095.
}

\section{Authors}

Hailiang Yu, A Kiet Tieu, Cheng Lu, Yanshan Lou, Xianghua Liu, Ajit R. Godbole, and Charlie Kong 


\title{
Tensile Fracture of Ultrafine Grained Al 6061 Sheets by Asymmetric Cryorolling for Microforming
}

\author{
Hailiang $\mathrm{YU}^{1,2 *}$, Kiet TIEU ${ }^{1}$, Cheng $\mathrm{LU}^{1}$, Yanshan $\mathrm{LOU}^{3}$, Xianghua $\mathrm{LIU}^{4}$, Ajit GODBOLE${ }^{1}$ and Charlie $\mathrm{KONG}^{5}$ \\ ${ }^{1}$ School of Mechanical, Materials \& Mechatronic Engineering, University of Wollongong, NSW 2500, Australia \\ ${ }^{2}$ School of Mechanical Engineering, Shenyang University, Shenyang 110044, China \\ ${ }^{3}$ Faculty of Engineering \& Industrial Science, Swinburne University of Technology, Hawthorn VIC 3122, Australia \\ ${ }^{4}$ State Key Laboratory of Rolling and Automation, Northeastern University, Shenyang 110004, China \\ ${ }^{5}$ Electron Microscope Unit, University of New South Wales, Sydney, NSW 2052, Australia
}

\begin{abstract}
The size effect on the mechanism of fracture in ultrafine grained sheets is an unsolved problem in microforming. This paper describes a tensile test carried out to study the fracture behavior and the shear fracture angles of both rolled and aged ultrafine grained Aluminum 6061 sheets produced by asymmetric cryorolling. A Scanning Electron Microscope (SEM) was used to observe the fracture surface. The finite element method was used to simulate the tensile test using the uncoupled Cockcroft-Latham and Tresca criteria and the coupled Gurson-Tvergaard-Needleman (GTN) damage criterion. It was found that the shear fracture angle decreases gradually from $90^{\circ}$ to $64^{\circ}$ with an increasing number of passes. The results of simulations using the GTN criterion show trends similar to the experimental ones. The paper also presents a discussion on the fracture mechanism and the size effect during the tensile test.
\end{abstract}

Keywords: Tensile test; Asymmetric cryorolling; Aluminum; Fracture; Damage criterion

\section{Introduction}

In recent years, micro-manufacturing has attracted increasing attention due to the trend of product miniaturization. The global market for microsystems reached \$25 billion in 2009 (Yurish et al. 2005), and continues to show a growing demand on micro-technical products. Most of these products contain mechanical parts produced by microforming. The microforming process demands a greater understanding of size effects and material behavior associated with miniaturization. In

\footnotetext{
* Corresponding author: YU HL, E-mail: hailiang@uow.edu.au or yuhailiang1980@tom.com
} 
particular, fracture in microforming has received increasing attention in recent years. Fu and Chan (2013) have carried out a review on the microforming technologies. They summarized that the fracture strain decreases with reduction in workpiece size and an increase in grain size in tensile tests of sheet metal. It was seen that fracture takes place through localized shearing of individual grain. However, there are still many unanswered questions on the fracture mechanism of micro-formed foils.

To reduce the size effects on the deformation of workpiece in the microforming process, it is possible to manufacture nanostructured/ultrafine grained sheet/foil by Severe Plastic Deformation (SPD) methods. Ma et al. (2009) studied the deformation of ultrafine grained copper produced by Equal Channel Angular Pressing (ECAP) in a micro deep drawing process. They found that the ultrafine grained copper has a potential application in microforming. The main advantages of nanostructured/ultrafine grained materials processed by SPD are good machinability, forgeability, and formablity, achieved at relatively low process cost. SPD techniques such as ECAP, Accumulative Roll Bonding (ARB) (Yu et al., 2013a), and Asymmetric Cryorolling (AC), have been developed (Estrin and Vinogradov, 2013) to this end. Among these techniques, ARB and AC can produce flat sheets. Wang et al. (2002) carried out cryorolling experiments with pure copper. They found that the matrix grains impart high strength and the inhomogeneous microstructure induces strain hardening that stabilize the tensile deformation. The microstructural evolution of a precipitation-hardenable cryorolled Al-Mg-Si alloy at different strain levels was studied by Panigrahi and Jayaganthan (2008). Yu et al. (2012, 2013b) studied the evolution of the microstructure of $\mathrm{Al} 1050$ and $\mathrm{Al} 6061$ alloys by AC. However, there have been no reports to date on the investigation of the fracture behavior of sheets when subjected to cryorolling.

The tensile test has been used widely to study the fracture behavior of metals. Thin rolled copper foils of varying thickness were tested in tension by Simons et al. (2006). They found that when the thickness is reduced from $250 \mu \mathrm{m}$ to $10 \mu \mathrm{m}$, the fracture strain decreases from approximately 20\% to $0.2 \%$ for as-received foils and from $35 \%$ to $15 \%$ for heat-treated samples. Fu and Chan (2011) conducted tensile tests with annealed pure copper foils with different thicknesses and grain sizes to study the size effects on fracture behavior. It was found that the flow stress, fracture stress and strain and the number of micro-voids on the fracture surface decrease with decreasing ratio of specimen size to grain size. To analyze the fracture mechanism, most researchers use the Scanning 
Electron Microscope (SEM) to observe the fracture surface of tensile samples. Based on the observation of the fracture surface, Segal et al. (2006) analyzed the fracture of ultrafine grained $(\mathrm{Al}+0.5 \% \mathrm{Cu})$ alloy during tensile tests. They found that the initial plasticity could be attributed to micro-localized flow along shear bands. For ultrafine grained metallic samples, flow localization in the neck is observed almost immediately after the yield stress is exceeded. The shear fracture angle $\alpha$ (Figure 1) may range from $45^{\circ}$ to $90^{\circ}$ for different materials, strain rates, etc. However, there are only a limited number of reports that mention the shear fracture angle. Khakbaz and Kazeminezhad (2012) found that the shear fracture angle increases from $45^{\circ}$ to $60^{\circ}$ in annealed samples after three passes of constrained groove pressing. Wang and Shan (2008) carried out tensile tests with ultrafine grained aluminum under different strain rates, and they found that the fracture angles of samples were about $60^{\circ}$ regardless of the strain rate. However, the reason for this phenomenon was still not clear. Labergère et al. (2011) employed a fully adaptive 2D numerical methodology to simulate with accuracy various metal forming processes, e.g. tensile testing. In their model, the mesh size distribution is based on various error indicators making use of the hessian of the plastic strain rate combined with a specific damage error function and a specific local curvature error function evaluated at contact boundaries. In their simulated and experimental results, the shear fracture angles of tensile samples are around $60^{\circ}$.

\section{Figure 1.}

Most metals subjected to tensile tests are tested to ductile fracture. Many ductile fracture criteria have been proposed. The basic principles upon which ductile fracture criteria are based can be generally divided into four categories (Vez Jr et al. 2010): (a) energy dissipation; (b) void growth: material modeling; (c) void growth: growth mechanisms; and (d) void growth: void geometry. These are exemplified by the Cockcroft-Latham (1968), the Tresca, the Freudenthal (1950), the Gurson-Tvergaard-Needleman (GTN) (Gurson 1977; Needleman and Tvergaard 1987) and the Continuum Damage Mechanics (CDM) or CDM-based (Kachanov 1986; Chow and Wang 1987; Lemaitre 1992; Lemaitre and Desmorat 2005; Lemaitre et al. 2009; Murakami 2012; Saanouni 2008, 2012 and 2013; Besson 2010) fracture criteria. Although these fracture criteria can predict the fracture behavior of metals, it is not clear which criteria can accurately predict the fracture for 
nanostructure/ultrafine grained materials.

Yu et al. (2013) reported that the grain size could be refined to $235 \mathrm{~nm}$ in Al 6061 alloy sheets after seven AC passes. This is an example of ultrafine grained material. In this paper, we present an analysis of the fracture of both rolled and aged Al 6061 alloy sheets subjected to tensile tests. The shear fracture angle gradually decreases as the number of rolling passes increases, and plateaus at around $60^{\circ}$. Along with the experimental investigation, Finite Element Method (FEM) simulations of the fracture using different fracture criteria are also presented. The results of simulations using the GTN damage criterion show trends similar to the experimental observations. An explanation for the stable fracture angle $\left(\sim 60^{\circ}\right.$, not $\left.45^{\circ}\right)$ is proposed.

\section{Sample evolution during tensile test}

Figure 2 illustrates the progressive evolution of a typical sample during a tensile test. Figure 2(a) shows uniform elongation; Figure 2(b) the slip line field during necking (Segal et al. 2006); followed by Fig 2(c), 2(d) and 2(e) showing different fracture models with different fracture angles. The following paragraphs elaborate on these individual stages.

Uniform elongation - Figure 2(a)

Corresponding to an elongation $\Delta l$, the true strain $\varepsilon$, the fractional reduction in cross-section area $\varphi$ and the true tensile stress $\sigma$ in rectangular cross section samples are:

$$
\begin{aligned}
& \varepsilon=\ln \left(1+\frac{\Delta l}{l_{0}}\right) \\
& \varphi=\frac{\Delta l}{\Delta l+l_{0}} \\
& \sigma=\frac{P}{(1-\varphi) A_{0}}
\end{aligned}
$$

where the $I_{0}$ is the initial sample length, $A_{0}$ the initial cross-section area, and $P$ the instantaneous tensile load.

\section{Figure 2.}

Necking-Figure 2 (b) 
Figure 2(b) shows the slip line field in the plastic zones ABDO during localized necking (Segal et al. 2006). Here, we assume that $\Delta l_{0}$ is the elongation before necking and $\Delta l_{1}$ the elongation after necking that deforms around the necking zones nearly equals to sample width $w$. Then, the true stain $\varepsilon_{\mathrm{n}}$, area reduction $\varphi_{\mathrm{n}}$, and true tensile stress $\sigma_{\mathrm{n}}$ are given by:

$$
\begin{aligned}
& \varepsilon_{n}=\ln \left[\left(1+\frac{\Delta l_{0}}{l_{0}}\right)\left(1+\frac{\Delta l_{1}}{w}\right)\right] \\
& \varphi_{n}=\frac{\Delta l_{0}}{\Delta l_{0}+l_{0}}+\frac{\Delta l_{1}}{\Delta l_{1}+w} \\
& \sigma_{n}=\frac{P}{\left(1-\varphi_{n}\right) A_{0}}
\end{aligned}
$$

\section{Fracture}

Necking is followed by sample fracture. Generally, ductile fracture often appears in metal sheets/foils, although shear fracture at angles ( $\alpha$ ) can also occur, as shown in Figures 2 (c) to 2(e). The following paragraphs describe the criteria that have been developed for prediction of the fracture behavior in materials.

1) Cockcroft-Latham fracture criterion (Cockcroft and Latham 1968; Haddi et al. 2012)

The criterion assumed that the maximum principal stress is the most relevant in the initiation of fracture. The criterion is defined in terms of traction plastic work associated with the principal stress along the path of the equivalent plastic strain, as shown in Eq. (7).

$$
\int_{0}^{\varepsilon_{f}} \sigma_{1} \mathrm{~d} \varepsilon_{e q}=C_{1}
$$

where $\sigma_{1}$ is the largest principal stress, $\varepsilon_{f}$ is the critical plastic strain at fracture, and $\varepsilon_{e q}$ is the equivalent plastic strain. $C_{1}$ is the critical damage value at fracture. In the tensile process, the largest principal stress is parallel to the loading direction. Thus, based on this criterion, the final fracture angle of samples after the tensile process will be around $90^{\circ}$, as shown in Figure 2 (c).

2) Tresca fracture criterion 
The Tresca criterion is based on the maximum shear stress, as shown in Eq. (8).

$$
\tau_{\max }=\frac{\sigma_{1}-\sigma_{3}}{2}=C_{2}
$$

In the tensile process, the maximum shear stress $\left(\tau_{\max }\right)$ is generally oriented at $45^{\circ}$ to the loading direction. According to this criterion, the samples will fracture as shown in Figure 2 (d).

\section{3) GTN fracture criterion}

The GTN fracture criterion, as shown in Eqs. (9) (13) (Gurson 1977; Needleman and Tvergaard 1987; Zhou and Ling 2009), has proved successful in predicting mechanical degradation and failure in tensile-dominant processes:

$$
\phi=\left(\frac{\sigma_{e q}}{\sigma_{0}}\right)^{2}+2 q_{1} f_{V} \cosh \left(\frac{3}{2} \frac{q_{2} \sigma_{H}}{\sigma_{0}}\right)-\left(1+q_{3} f_{V}^{2}\right)
$$

where, $\phi$ is the plastic potential in which the parameters $q_{1}, q_{2}$ and $q_{3}$ are material coefficients, $\sigma_{e q}$ the equivalent von Mises stress, $\sigma_{H}$ the hydrostatic stress, $\sigma_{0}$ the current flow stress of the matrix material and $f_{V}$ is the void volume fraction which is defined by:

$$
f_{V}= \begin{cases}f, & f \leq f_{c} \\ f_{c}+\frac{f_{u}^{*}-f_{c}}{f_{f}-f_{c}}\left(f-f_{c}\right) & f>f_{c}\end{cases}
$$

where $f$ defines the current void volume fraction; $f_{f}$ is the void volume fraction at failure and $f_{c}$ the void volume fraction at a critical juncture when $f$ starts to deviate from $f_{V} ; f_{u}^{*}$ is the value of $f_{V}$ at fracture. To complete the constitutive model, the void volume fraction has to be established as a function of time. The growth of existing voids $\left(\dot{f}_{\text {growth }}\right)$ and the nucleation of new voids $\left(\dot{f}_{\text {nucleation }}\right)$ contribute to the increase in porosity:

$$
\dot{f}=\dot{f}_{\text {growth }}+\dot{f}_{\text {nucleation }}
$$

where

$$
\begin{gathered}
\dot{f}_{\text {growth }}=(1-f) \dot{\varepsilon}_{k k}^{p} \\
\dot{f}_{\text {nucleation }}=\frac{f_{N}}{s_{N} \sqrt{2 \pi}} \exp \left\{-\frac{1}{2}\left[\frac{\varepsilon_{e}^{p}-\varepsilon_{N}}{s_{N}}\right]\right\} \dot{\bar{\varepsilon}}^{P}
\end{gathered}
$$


where $\dot{\varepsilon}_{k k}^{p}$ is the trace of the equivalent plastic strain rate, $\dot{\bar{\varepsilon}}^{P}$ the plastic strain rate, $f_{N}$ the volume fraction of particles available for void nucleation, $\varepsilon_{N}$ the main void nucleation strain, and $s_{N}$ the standard deviation of the distribution. The main parameters in the GTN criterion are listed in Table 1 (Zhou and Ling 2009).

Three-dimensional FE models for the first, third, fifth and seventh passes were set up on the LS-DYNA platform, using the experimental sample dimensions and material parameters. The stress-strain relations used follow the values in Yu et al. (2013) with a piecewise stress vs strain model, where the failure void volume fraction $\left(f_{f}\right)$ gradually decreases with an increasing number of passes. The Solid 164 type was employed which was solved by explicit dynamic finite element method. In order to reduce the influence of mesh size distribution on the simulated results (Sánchez et al. 2008), the parallel tensile zones were meshed with uniform element size. In addition, samples were meshed with 8-node hexahedral elements. The smallest of element was measured $0.25 \mathrm{~mm}$ (length) $\times 0.22 \mathrm{~mm}$ (width) $\times 0.22 \mathrm{~mm}$ (thickness). In the model for the first pass, there are 29435 nodes and 24153 elements in the samples.

\section{Table 1.}

\section{Experimental investigation}

\section{Procedure}

Commercial Al 6061 alloy specimens were used. The chemical composition of the alloy is listed in Table 2. Before rolling, the samples were well tempered. The AC technique was employed to roll sheets measuring $1.5 \mathrm{~mm} \times 60 \mathrm{~mm} \times 200 \mathrm{~mm}$. The rolling speed ratio between the upper and lower rolls was set at 1.1. The sheets were dipped into liquid nitrogen for at least 8 minutes before each pass. The rolling schedule is shown in Table 3. After each AC pass, half of the samples were aged at $100^{\circ} \mathrm{C}$ for 48 hours. The samples were machined into $25 \mathrm{~mm}$ gauge length and $6 \mathrm{~mm}$ gauge width tensile samples according to ASTM D412 standard. Uniaxial tensile tests were conducted with an initial strain rate of $1.0 \times 10^{-3} \mathrm{~s}^{-1}$ on an INSTRON machine operating at constant speed. SEM was used to reveal details of the fracture mechanism after each pass. The morphology of the fractured surface of the sheets was studied with a Zeiss Auriga Field Emission Scanning Electron Microscope (FESEM) operating at $20 \mathrm{kV}$ with a working distance of $15 \mathrm{~mm}$. 


\section{Table 2.}

Table 3.

\section{Shear Fracture Angle}

In this study, we focused on an investigation of the fracture behavior of ultrafine grained $\mathrm{Al} 6061$ alloy sheets subjected to tensile processing. Table 4 lists a series of images of the tips of the fractured samples and the corresponding shear fracture angles. After the first AC pass, significant necking was observed. The shear fracture angles for rolled and aged samples were seen to be $90.0^{\circ}$ and $87.9^{\circ}$ respectively. These reduced sharply to $72.4^{\circ}$ and $71.6^{\circ}$ respectively after the second AC pass. With subsequent passes, the shear fracture angle decreased gradually, but at a slower rate. After the seventh AC pass, the shear fracture angle was seen to be $64.3^{\circ}$ for both rolled and aged samples. Besides, for the samples after two or three AC passes, the specimen width at fracture zone changes slightly during tensile, and there was less necking before the final ductile fracture. The reduction in necking decreases the tri-axial nature of the stress at final ductile fracture. Shear ductile fracture takes place at relatively low-stress triaxiality, while at higher stress triaxiality with severe necking, coalescence of voids is caused by necking of the inter-void ligaments instead of shear-linking up of voids (Lou et al. 2012 and 2013). Thus, this results in reducing the shear fracture angle from $90^{\circ}$ to about $64.3^{\circ}$.

\section{Table 4.}

The shear fracture angles and the elongation after each pass for both rolled and aged samples are presented in Figure 3. It is seen that the shear fracture angle decreases and levels off with increasing the number of AC passes to about $64^{\circ}$, instead of $45^{\circ}$, as generally assumed. After the fourth pass, the shear fracture angle for rolled samples is slightly larger than that for aged samples.

\section{Figure 3.}

\section{Fracture morphology}

Figure 4 shows SEM images of the fracture surfaces of rolled and aged samples after tensile tests. After the first AC pass, a large number of round dimples appear on the fracture surface. This suggests that after the first pass, the fracture is evidently caused by inter-void necking of ligaments at relatively high stress triaxiality induced by severe necking at fracture. After several passes, the depth of dimples decreases for both the rolled and aged samples. It is observed that the dimples link 
up along a certain shear direction with each successive pass. The dimple depth gradually decreases along a definite direction, which indicates shear fracture. The transition from inter-void necking of ligaments to shear-linking up of voids as passes increases is due to the decrease of stress triaxiality caused by reduced necking at the eventual fracture. After the seventh AC pass, the dimples are very shallow. Moreover, as shown in Figure 4 (e) and (f), and Figure 4 (g) and (h), the dimples are smooth for rolled samples, while there are some wrinkles on the dimple surface for the aged samples.

\section{Figure 4.}

\section{Discussion}

\section{Fracture Mechanism in Tensile Process}

In a typical uniaxial tensile test, the shear fracture angle is always $90^{\circ}$ or $45^{\circ}$ for typical FCC metals and alloys. Ma et al. (2013) found that the shear fracture angle is $90^{\circ}$ for ultrafine grained copper sheets. Segal et al. (2006) established a mathematical model for tensile testing of ultrafine grained metals. They predicted a $45^{\circ}$ fracture angle for cylindrical samples, and realized it in ultrafine grained $\mathrm{Al}-0.5 \% \mathrm{Cu}$ alloy. However, as seen in Table 4, the shear fracture angle gradually decreases from $90^{\circ}$ to $64^{\circ}$, and is a function of the number of passes to which the sample is subjected. Khakbaz (2012) and Wang (2008) found that the shear fracture angles range from $60^{\circ}$ to $65^{\circ}$ for ultrafine grained aluminum samples produced by SPD techniques. Labergère et al. (2011) employed a fully adaptive 2D numerical methodology to simulate a tensile testing and the shear fracture angles of tensile samples were around $60^{\circ}$.

Figure 5 shows the shear fracture angle as a function of the number of passes, as predicted by the different fracture criteria described above. The Cockcroft-Latham fracture criterion predicts a constant $90^{\circ}$ shear fracture angle which is the same with the results of Kang et al. (2014) who conducted the tensile tests with $8.15 \mathrm{~mm}$ thickness of AA6061, while the Tresca fracture criterion predicts a constant $45^{\circ}$. It is obvious that these two fracture criteria cannot predict the fracture behavior of ultrafine grained aluminum alloys produced by SPD techniques. In contrast, application of the GTN criterion in the FE model yields simulation results that have a trend similar to the experimental ones. The AC-processed aluminum sheets are ultrafine grained materials, whose ductility reduces with an increasing number of rolling passes. In Figure 4, there are some dimples in 
the fracture surface, which implies ductile fracture behavior during the tensile process, but there are also some smooth zones at the fracture surface, suggesting localized brittle fracture. Segal et al. (2006) found that both ductile and brittle fractures can occur in the samples during tensile tests. When the GTN criterion was employed, the brittle fracture behavior of samples was neglected and the element size cannot be meshed too small. This may explain the difference between the simulated results and experimental ones. In addition, because the brittle fracture behavior of the samples was neglected, the simulated final elongations are larger than those seen experimentally. However, it appears that the GTN criterion can still be used to simulate the fracture behavior of ultrafine grained samples during tensile tests compared with other two kinds of fracture criteria.

\section{Figure 5.}

Secondary particles can lead to crack initiation and induce surface defects in the deformed material. As shown in Figure 6, there are some voids around the particles on the fracture surface. In the rolled samples, as the number of rolling passes increases, an increasing number of voids appear around the particles (Yu et al. 2008, 2009, 2013b). Figure 6 (a) shows the voids formed around the secondary particles after rolling. Figures 6(b) and 6(c) shows the fracture mechanism by coalescence of voids for necking of inter-void ligaments and shear-linking up of voids respectively (Weck and Wilkinson 2008). Compared with the two different mechanisms of void coalescence in Figures 6(b) and 6(c) with the SEM images of fracture surfaces for specimens after a different number of rolling passes, it is obvious that coalescence of voids transitions from inter-void necking of ligaments to shear-linking up of voids as the number of rolling passes increases.

\section{Figure 6.}

Eqs. (12) and (13) describe the void growth and nucleation in the GTN model. The GTN model also considers the coalescence of voids as an important factor for the growth of the void volume fraction, as in Eq. (10). Besides, a number of other models have been proposed to describe void coalescence according to the two different mechanisms illustrated in Figures 6(b) and 6(c). These two mechanisms are schematically illustrated in Figure 7. Based on different assumptions, three typical void coalescence models (Thomason 1990; McClintock et al. 1966; Lou et al. 2012) were proposed:

Figure 7. 


$$
\begin{aligned}
& \left(\frac{0.3 A_{n-2 D}}{a / c\left(1-A_{n-2 D}\right)}+0.6\right)\left(1-V_{f}\right)^{-1}=\frac{\sigma_{m}}{\sigma_{e}}+0.5 \\
& \frac{W}{c}=\exp \left[\frac{\sqrt{3} \bar{\varepsilon}}{2(1-n)} \sinh \frac{3(1-n)}{2}+\ln \sqrt{1+3 \bar{\varepsilon}^{2}}\right] \\
& D_{c}=D_{c}\left(\frac{\tau_{\max }}{\sigma_{e}}\right)
\end{aligned}
$$

In the above equations, $a, c, e$, and $W$ are geometric parameters of voids as shown in Figure 7; $A_{n-2 D}$ is the area fraction of the inter-void matrix, which is equal to $e / W ; V_{f}$ the initial void volume fraction; $\sigma_{m}$ the mean stress; $\sigma_{e}$ the equivalent plastic stress; $\bar{\varepsilon}$ the far-field true strain; $n$ the strain hardening exponent; $\tau_{\max }$ the maximum shear stress. Eq. (14) is controlled by the normal stress, and Eqs. (15) and (16) are controlled by shear stress. It is easy to understand that both the normal stress and shear stress together determine the coalescence of voids in the AC-processed aluminum sheets. Thus, to simulate the fracture behavior of sheet metal materials in the tensile process, the void coalescence under both tension and shear loading should be considered. It will be interesting to develop a void coalescence model that combines tension and shear in future. Here, we simply define a weighting factor $\beta$, which stands for the fraction of shear-linking up of voids $\left(f_{s}\right)$ compared to the fraction of the inter-void necking of ligaments $\left(f_{N}\right)$ in the shear fracture angle $(a)$ of samples in the tensile processing:

$$
(1-\beta) f_{N}+\beta f_{S}=\alpha
$$

Figure 8 shows the relationship between the weighting factor and the foil thickness $(t)$, which could be fitted by Eq. (18):

$$
\beta=0.5635-0.0043 \exp (t / 0.27)
$$

\section{Figure 8.}

\section{Size Effect}

Figure 3 shows that the elongation of samples increases after the ageing treatment compared to that after rolling. However, rolled and aged specimens subjected to the tensile test show only a very slight difference. The rolled samples were aged at $100^{\circ} \mathrm{C}$, which does not result in an increase in grain size and only develops some nano-size precipitations. The precipitations result in greater 
elongation during the tensile test, owing to an accumulation of dislocations. The dislocations surround the nano-size precipitates, which results in enhanced ductility. Thus, from the experimental results, it may be concluded that the precipitations do not affect the shear fracture angle. In addition, as seen in Figure 3, the shear fracture angle increases with the number of rolling passes. During rolling, the sheet thickness gradually decreases from $1.3 \mathrm{~mm}$ to $0.19 \mathrm{~mm}$, and the grain size gradually decreases to $235 \mathrm{~nm}$. Thus, both the grain size and the thickness of samples resulting from the rolling will affect the fracture behavior of the samples in the tensile test.

Figure 9(a) compares the tensile force vs displacement curve deduced from simulation using the GTN criterion with the experimental results. The simulated final elongations are seen to exceed the experimental results. In the simulation models, the material properties are assumed to be uniform and inhomogeneity. This may explain the discrepancy between the simulation results and the experimental results. However, as shown in Figure 3, we found that the influence of the sample elongation during tensile process on the shear fracture angle is only slight. The shear fracture angles are similar for a wide range of elongations, for the rolled and aged samples with the same thickness. Thus, it can be concluded that the difference between the simulated and experimental elongations do not imply an incorrect estimate of the shear fracture angle. Figure 9 (b) shows the shear fracture angles with a variety of the thickness and material parameters of samples by the GTN criterion. As seen in Table 3, after the first AC pass, the thickness of sample is $1.3 \mathrm{~mm}$. When using the material parameter after the first pass, the shear fracture angle is $90^{\circ}$, however, when using the material parameters after the fifth pass, the shear fracture angle decreases to $74^{\circ}$. Similarly, for the sample thickness after the fifth AC pass, when using the material parameters after the first AC pass, the shear fracture angle is $64^{\circ}$, which decreases into $60^{\circ}$ when using the material parameters after the fifth AC pass. It is obvious that the material characteristics will directly affect the shear fracture angle during the tensile test.

When using the same material parameters with variable sample thicknesses, the shear fracture angles will also change greatly. When using the material parameters after the first AC pass, the shear fracture angles is $90^{\circ}$ when the thickness of sample is $1.3 \mathrm{~mm}$. This reduces to $64^{\circ}$ when the thickness reduces to $0.4 \mathrm{~mm}$ after the fifth AC pass. Similarly, when using the material parameters after the fifth AC pass, the shear fracture angles is $74^{\circ}$ for thickness of sample $1.3 \mathrm{~mm}$. This decreases to $60^{\circ}$ for a $0.4 \mathrm{~mm}$ sample thickness. 


\section{Figure 9.}

Characteristic features of localization and fracture were detected during tensile testing of samples. According to Eqs. (9) - (13), the fracture behavior is directly affected by the void density. Uniform elongation takes place along sample length with a symmetrical stress-strain state and a pure shear deformation mode. When the material hardening ability reduces to some critical level, plastic deformation is localized in the sample neck (Segal et al. 2006). In the tensile test processing, both the necking fracture and shear fracture models have obvious shear lines. In addition, the fractures initiate at the center of the samples. Figure 10 shows two kinds of fracture behavior, and Figure 10 (g) is the employed geometry and mesh of samples. Sánchez et al (2008) employed the GTN criterion to solve ductile fracture problems and pointed out particular attention should be given to the mesh size dependence and to the coalescence of the larger void. Saanouni (2012) also pointed out the fracture zone is very dependent in the mesh size and mesh orientation. In order to obtain a good result, the samples were meshed uniformly. Figure 10 (a) and (d) show the void density distribution before the fracture, the area with high void density in Figure 10 (a) is much larger than that in Figure 10 (d), which will directly affect the size of the initiated fracture, as shown in Figure 10 (b) and (e). As shown in Figure 10 (c) and (f), when the fracture initiates, they propagate along different directions, and shows different shear fraction angles of samples finally. When the area of the initiated fracture is larger than a certain value, the fracture will occur with necking. However, for the samples with a smaller size of fracture, the flow of samples is unstable. When the area of the initiated fracture is smaller than a certain value, the fracture will appear with shear model. As shown in Figure 3, with a higher pass number, the dimple depths decreases, which indicates that the $f_{f}$ will decrease, and then results in a lower shear fracture angle, as listed in Table 4.

Figure 10.

It is obvious that the shear fracture angle will reflect the elongation of the samples during the tensile process. Thus, the elongation of samples will change with thickness for the same material. With a reduction in the sheet thickness, the grains on the free surface are less constrained and more easily deformed at a substantially lower flow stress than is the case in the bulk state. Suh et al. (2010) found that the tensile strength of Al 6K21-T4 sheets decreased almost linearly with thickness when the thickness was reduced below a critical value. Figure $\mathbf{1 1}$ shows the FE simulation results 
of the elongation of samples during tensile test with the material parameters after the first AC pass with change of the sample thickness after the first, third, fifth, and seventh passes listed in Table 3. We could find that with the same material parameters, the fracture occurs by necking when the thickness is $1.3 \mathrm{~mm}$. However, when the thickness of samples is less than $0.8 \mathrm{~mm}$, the fracture occurs by shear. In addition, when the thickness of samples is $1.3 \mathrm{~mm}$, the elongation is about 3.0 $\mathrm{mm}$; however, it reduces to $2.0 \mathrm{~mm}$ when the thickness of sample is $0.2 \mathrm{~mm}$. It is obvious that the elongation of samples reduces with decreasing the sample thickness from $1.3 \mathrm{~mm}$ to $0.2 \mathrm{~mm}$, in which the elongation of samples are linearly proportional to the sample thickness, as was also seen by Suh et al. (2010).

\section{Figure 11.}

Figure 11 shows that the elongation is inversely proportional to the sample thickness. Figure 12 shows the relationship elongation/thickness as a function of the number of passes. It can be deduced that the effective ductility increases with more passes. After the seventh pass, the effective ductility is about two times that after the first pass.

\section{Figure 12.}

\section{Conclusions}

(1) The fracture behavior of ultrafine grained Al 6061 alloy sheets produced by asymmetric cryorolling was investigated both experimentally and by FE simulation. Experimental results showed that the shear fracture angle of the samples gradually decreases from $90^{\circ}$ to $64^{\circ}$ as the number of rolling passes increases.

(2) The fracture surface of the rolled samples is much smoother than that of the aged samples. This may be due to precipitation, and may explain the difference in elongation during the tensile test. However, precipitation does not appear to affect the shear fracture angle.

(3) Beside the material properties and the strain rate, the test specimen thickness affects the fracture behavior during the tensile test. For the same material parameter, the shear fracture angle during the tensile test reduces with reduction in sample thickness from $1.3 \mathrm{~mm}$ to $0.2 \mathrm{~mm}$.

(4) It would be interesting to develop a model based on void coalescence combining tension and shear in the future to predict the fracture behavior in nanostructured / ultrafine grained materials. 


\section{Acknowledgements}

The lead author acknowledges the financial support from the Vice-Chancellor's Fellowship Grant and URC small grant at the University of Wollongong, and from the National Natural Science Foundation of China through Grant 51105071.

\section{References}

Besson, J. (2010) Continuum models of ductile fracture: a review, International Journal of Damage Mechanics,19: 3-52.

Chow, C.L. and Wang, J. (1987) An anisotropic theory of continuum damage mechanics for ductile fracture, Engineering Fracture Mechanics, 27: 547-558.

Cockroft, M.G. and Latham, D.J. (1968) Ductile and workability of metals, Journal of The Institute of Metals, 96: 33-39.

Estrin, Y. and Vinogradov, A. (2013) Extreme grain refinement by severe plastic deformation: A wealth of challenging science, Acta Materialia, 61: 782-817.

Freudenthal, F.A. (1950) The Inelastic Behavior of Solids. Wiley, New York.

Fu, M.W. and Chan, W.L. (2011) Geometry and grain size effects on the fracture behavior of sheet metal in micro-scale plastic deformation, Materials and Design, 32: 4738-4746.

Fu, M.W. and Chan, W.L. (2013) A review on the state-of-the-art microforming technologies, International Journal of Advanced Manufacturing Technology, 67: 2411-2437.

Gurson, A.L. (1997) Continuum theory of ductile rupture by void nucleation and growth. Part 1yield criteria and flow rules for porous ductile media, Journal of Engineering Materials and Technology, 99: 2-15.

Haddi, A., Imad, A. and Vega, G. (2012) The influence of the drawing parameters and temperature rise on the prediction of chevron crack formation in wire drawing, International Journal of Fracture, 176: 171-180.

Kachanov, L.M. (1986) Introduction to continuum damage mechanics. Martinus Nijhoff Publichers, Dordrecht.

Kang, S.H., Lee, Y.S. and Lee H.W. (2014) Evaluation of flow stress and damage index at large plastic strain by simulating tensile test of Al6061 plates with various grain sizes, International Journal of Mechanical Sciences, 80: 54-61. 
Khakbaz, F. and Kazeminezhad, M. (2012) Strain rate sensitivity and fracture behavior of severely deformed Al-Mn alloy sheets, Materials Science and Engineering A, 532: 26-30.

Labergère, C., Rassineux, A. and Saanouni, K. (2011) 2D adaptive mesh methodology for the simulation of metal forming process with damage, International Journal of Materials Forming, 4: 317-328.

Lederer, M., Groger, V., Khatibi, G., et al. (2010) Size dependency of mechanical properties of high purity aluminium foils, Materials Science and Engineering A, 527: 590-599.

Lemaitre, J. (1996) A course on damage mechanics. Springer-Verlag, Doi: 10.1007/978-3-642-18255-6.

Lemaitre, J. and Desmorat, R. (2005) Engineering damage mechanics: Ductile, Creep, Fatigue and Brittle failures. Springer, Amsterdam.

Lemaitre, J., Chaboche, J.L., Benallal, A., Desmorat, R. (2009) Méchanique des matériaux solides. Dunod (3rd edition), Paris.

Lou, Y.S., Huh, H., Lim, S.J., et al. (2012) New ductile fracture criterion for prediction of fracture forming limit diagrams of sheet metals, International Journal of Solids and Structure, 49: 3605-3615.

Lou, Y.S., Yoon, J.W. and Huh, H. (2014) Modeling of shear ductile fracture considering a changeable cut-off value for stress triaxiality, International Journal of Plasticity, 54: 56-80.

Ma, E. (2003) Instabilities and ductility of nanocrystalline and ultrafine-grained metals, Scripta Materialia, 49: 663-668.

Ma, X., Lapovok, R., Gu, C., et al. (2009) Deep drawing behavior of ultrafine grained copper: modeling and experiment, Journal of Materials Sciences, 44: 3807-3812.

McClintock, F.A., Kaplan, S.M. and Berg, C.A. (1966) Ductile fracture by hole growth in shear bands, International Journal of Fracture Mechanics, 2: 614-627.

Murakami, S. (2012) Continuum damage mechanics: A continuum mechanics approach to the analysis of damage and fracture, Springer-Verlag, Dordrecht.

Needleman, A. and Tvergaard, V. (1987) An analysis of ductile rupture modes at a crack tip, Journal of the Mechanics and Physics of Solids, 35: 151-183.

Panigrahi, S., Jayaganthan, R. and Chawla, V. (2008) Effect of cryorolling on microstructure of Al-Mg-Si alloy, Materials Letters, 62: 2626-2629. 
Saanouni, K. (2008) On the numerical prediction of the ductile fracture in metal forming. Engineering Fracture Mechanics, 75: 3545-3559.

Saanouni, K. (2012) Damage mechanics in metal forming: Advanced modeling and numerical simulation, ISTE/Wiley, London.

Saanouni, K. (2013) Ductile damage prediction in metal forming processes: advanced modeling and numerical simulation, AIP Conference Proceeding, 1532: 30-37.

Sánchez, P.J., Huespe, A.E. and Oliver, J. (2008) On some topics for the numerical simulation of ductile fracture, International Journal of Plasticity, 24: 1008-1038.

Segal, V.M., Ferrasse, S. and Alford, F. (2006) Tensile testing of ultra fine grained metals, Materials Science and Engineering A, 422: 321-326.

Suh, C.H., Jung, Y.C. and Kim, Y.S. (2010) Effects of thickness and surface roughness on mechanical properties of aluminium sheets, Journal of Mechanical Science and Technology, 24:2091-2098.

Thomason, P.F. (1990) Ductile fracture of metals. Oxford: Pergamon Press.

Vaz Jr, M., De Santi Jr, N. and De Souza Neto, E.A. (2010) Numerical prediction of ductile failure onset under tensile and compressive stress states. International Journal of Damage Mechanics, 19: 175-195.

Wang, M. and Shan, A. (2008) Effect of strain rate on the tensile behavior of ultra-fine grained pure aluminum, Journal of Alloys and Compounds, 455: L10-L14.

Wang, Y.M., Chen, M.W., Zhou, F.H., et al. (2002) High tensile ductility in a nanostructured metal, Nature, 419 : 912-915.

Yang, S.S., Zhou, J.X., Ling, X., et al. (2012) Effect of geometric factors and processing parameters on plastic damage of SUS304 stainless steel by small punch test, Materials and Design, 41: 447-452.

Yu, H.L., Liu, X.H., Bi, H.Y. and Chen, L.Q. (2009) Deformation behavior of inclusions in stainless steel strips during multi-pass cold rolling, Journal of Materials Processing Technology, 209: 455-461.

Yu, H.L., Liu X.H. and Li, X.H. (2008) FE analysis of inclusion deformation and crack generation during cold rolling with a transition layer, Materials Letters, 62: 1595-1598.

Yu, H.L., Lu, C., Tieu, K., et al. (2012) Asymmetric cryorolling for fabrication of nanostructural 
aluminum sheets, Scientific Reports, 2: art.772.

Yu, H.L., Lu, C., Tieu, A.K., et al. (2013a) Fabrication of ultra-thin nanostructured bimetallic foils by accumulative roll bonding and asymmetric rolling, Scientific Reports, 3: art. 2373.

Yu, H.L., Tieu, A.K., Lu, C., et al. (2013b) Mechanical properties of Al-Mg-Si alloy sheets produced using asymmetric cryorolling and ageing treatment, Materials Science and Engineering A, 568: 212-218.

Yurish, S., Kirianaki, N. and Myshkin, I. (2005) World sensors and MEMS markets: analysis and trends, Sensors \& Transducers, 62: 456-461.

Weck, A. and Wilkinson, D.S. (2008) Experimental investigation of void coalescence in metallic sheets containling laser drilled holes, Acta Materialia, 56: 1774-1784. 
Table 1. Main parameters in GTN model.

\begin{tabular}{lcccccccc}
\hline Parameters & $f_{0}$ & $f_{\mathrm{c}}$ & $f_{\mathrm{N}}$ & $\varepsilon_{N}$ & $s_{\mathrm{N}}$ & $\boldsymbol{q}_{\mathbf{1}}$ & $\boldsymbol{q}_{\mathbf{2}}$ & $\boldsymbol{q}_{\mathbf{3}}$ \\
\hline Value & 0.000125 & 0.013 & 0.0008 & 0.3 & 0.1 & 1.5 & 1.0 & 2.25 \\
\hline
\end{tabular}


Table 2. Chemical composition of Al 6061 alloy.

\begin{tabular}{cccccccccc}
\hline Elements & Si & Fe & Cu & Mn & Mg & Zn & Ti & Cr & Al \\
\hline wt \% & $0.4-0.8$ & 0.7 & $0.15-0.4$ & 0.15 & $0.8-1.2$ & 0.25 & 0.15 & $0.04-0.35$ & Balance \\
\hline
\end{tabular}


Table 3. Schedule of asymmetric cryorolling.

\begin{tabular}{ccccccccc}
\hline Rolling pass & 0 & 1 & 2 & 3 & 4 & 5 & 6 & 7 \\
\hline Strip thickness, mm & 1.5 & 1.3 & 1.0 & 0.82 & 0.58 & 0.4 & 0.26 & 0.19 \\
Reduction ratio, \% & - & 13 & 23 & 18 & 29 & 31 & 35 & 27 \\
\hline
\end{tabular}


Table 4. Image of fracture end of samples after tensile test.

\begin{tabular}{|c|c|c|c|c|}
\hline \multirow{2}{*}{$\begin{array}{c}\text { Number of } \\
\text { rolling pass, } \mathbf{N}\end{array}$} & \multicolumn{2}{|c|}{ Images } & \multicolumn{2}{|c|}{ Shear fracture angle, ${ }^{\circ}$} \\
\hline & Rolled samples & Aged samples & Rolled samples & Aged samples \\
\hline Pass 1 & & & $90 \pm 0$ & $87.9 \pm 2.8$ \\
\hline Pass 2 & & & $72.4 \pm 1.0$ & $71.6 \pm 0.4$ \\
\hline Pass 3 & & & $70.8 \pm 0.3$ & $67.7 \pm 0.5$ \\
\hline Pass 4 & & & $67.1 \pm 1.7$ & $66.7 \pm 1.0$ \\
\hline Pass 5 & & & $64.7 \pm 0.3$ & $66.0 \pm 0.2$ \\
\hline Pass 6 & & & $64.3 \pm 0.3$ & $66.4 \pm 0.3$ \\
\hline Pass 7 & & & $64.3 \pm 0.4$ & $64.3 \pm 0.5$ \\
\hline
\end{tabular}


Shear fracture angle after tensile process

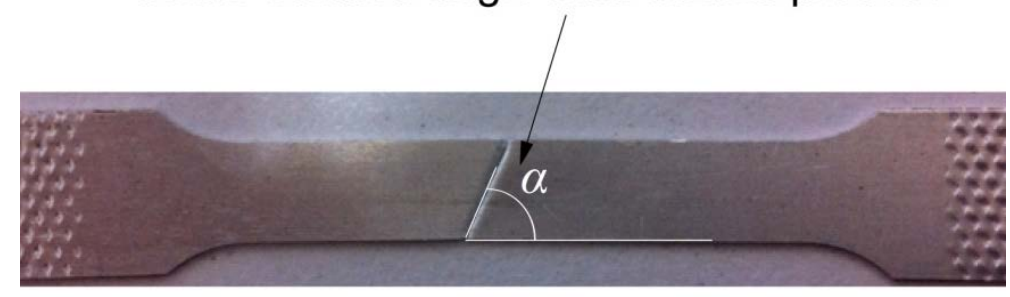

Figure 1. Illustration of shear fracture angle. 


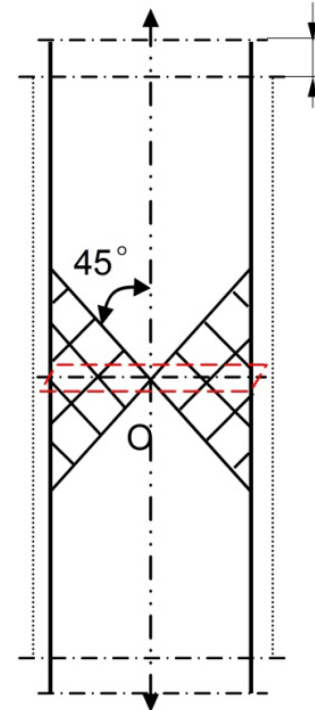

(a)

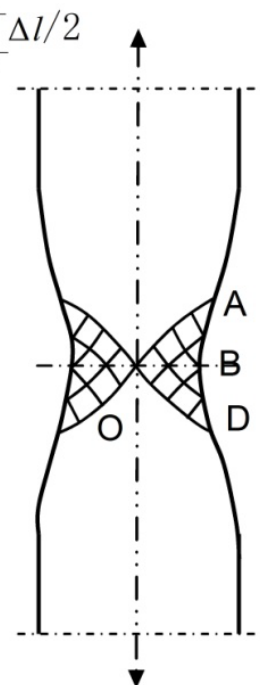

(b)

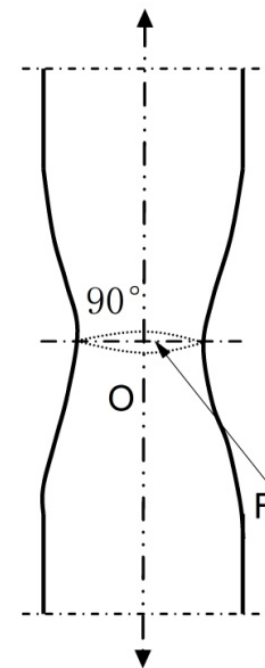

(c)

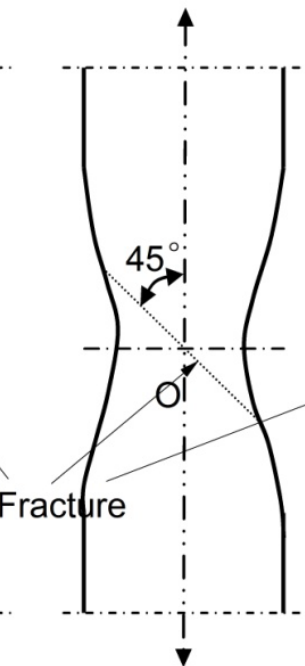

(d)

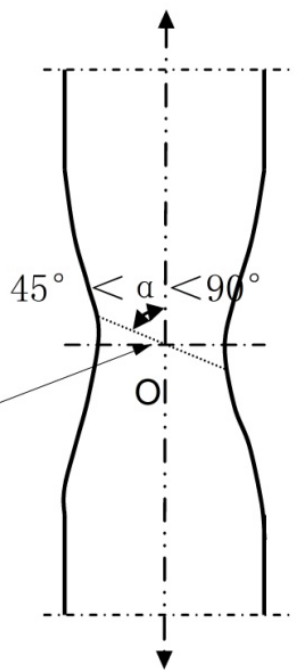

(e)

Figure 2. Evolution of samples during tensile press (a) uniform elongation; (b) slip line field during necking; (c) Cockroft-Latham fracture model; (d) Tresca fracture model; (e) GTN fracture model. 


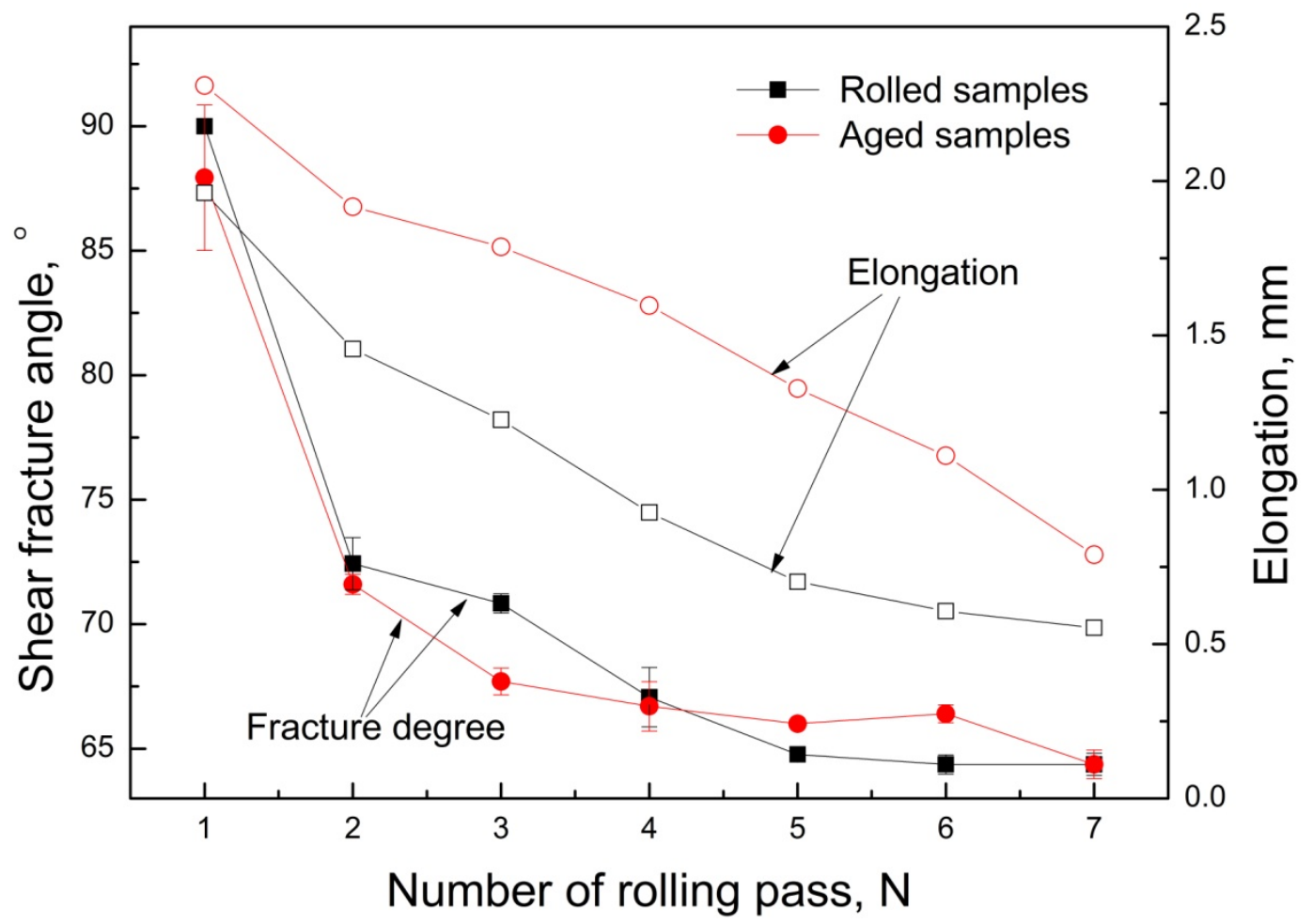

Figure 3. Fracture degree and elongation for rolled and aged samples in tensile test. Scatter bar of fracture angles for pass 5 and 6 not shown due to small values. 

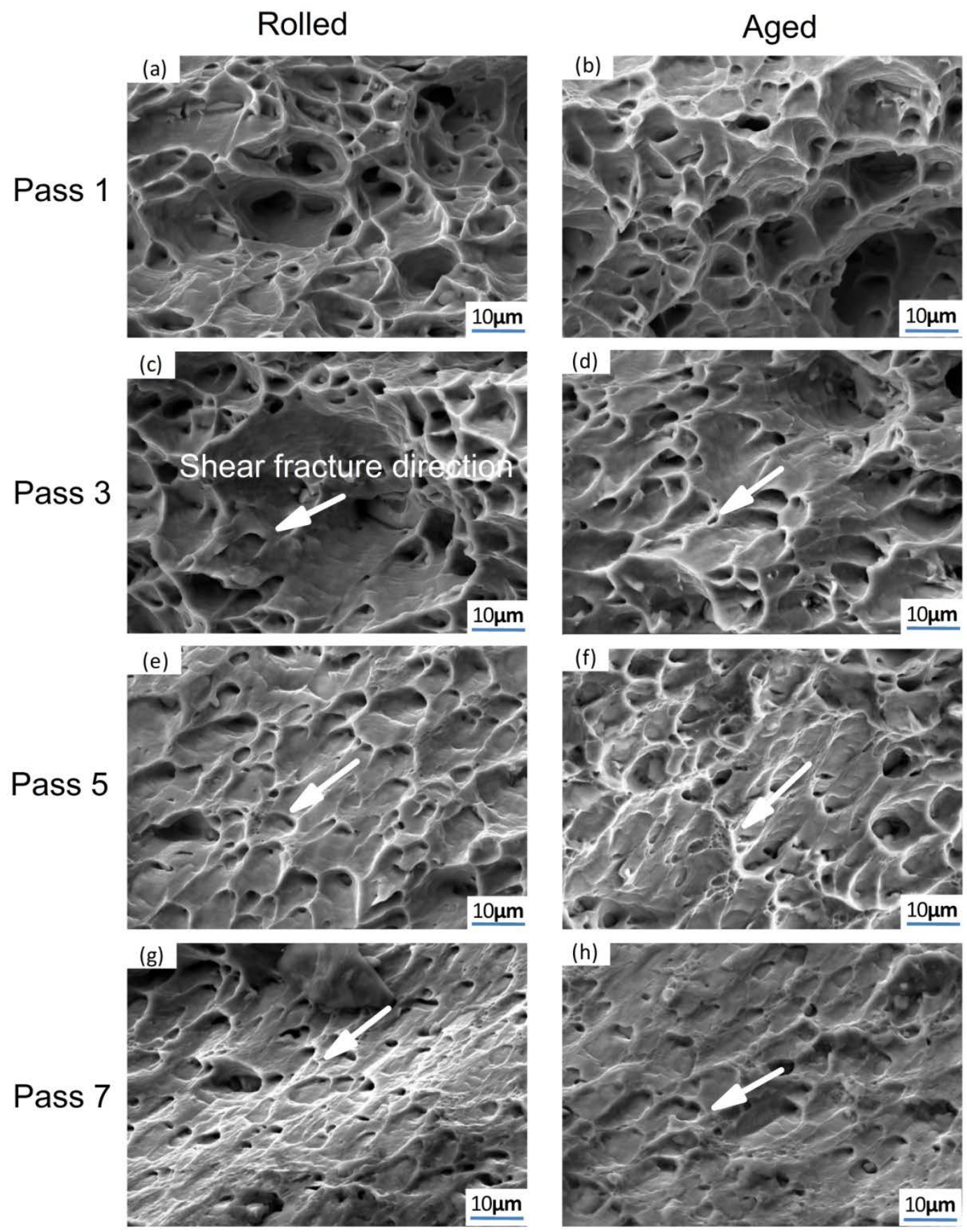

Figure 4. Fracture morphology of rolled and aged samples after multiple passes. 


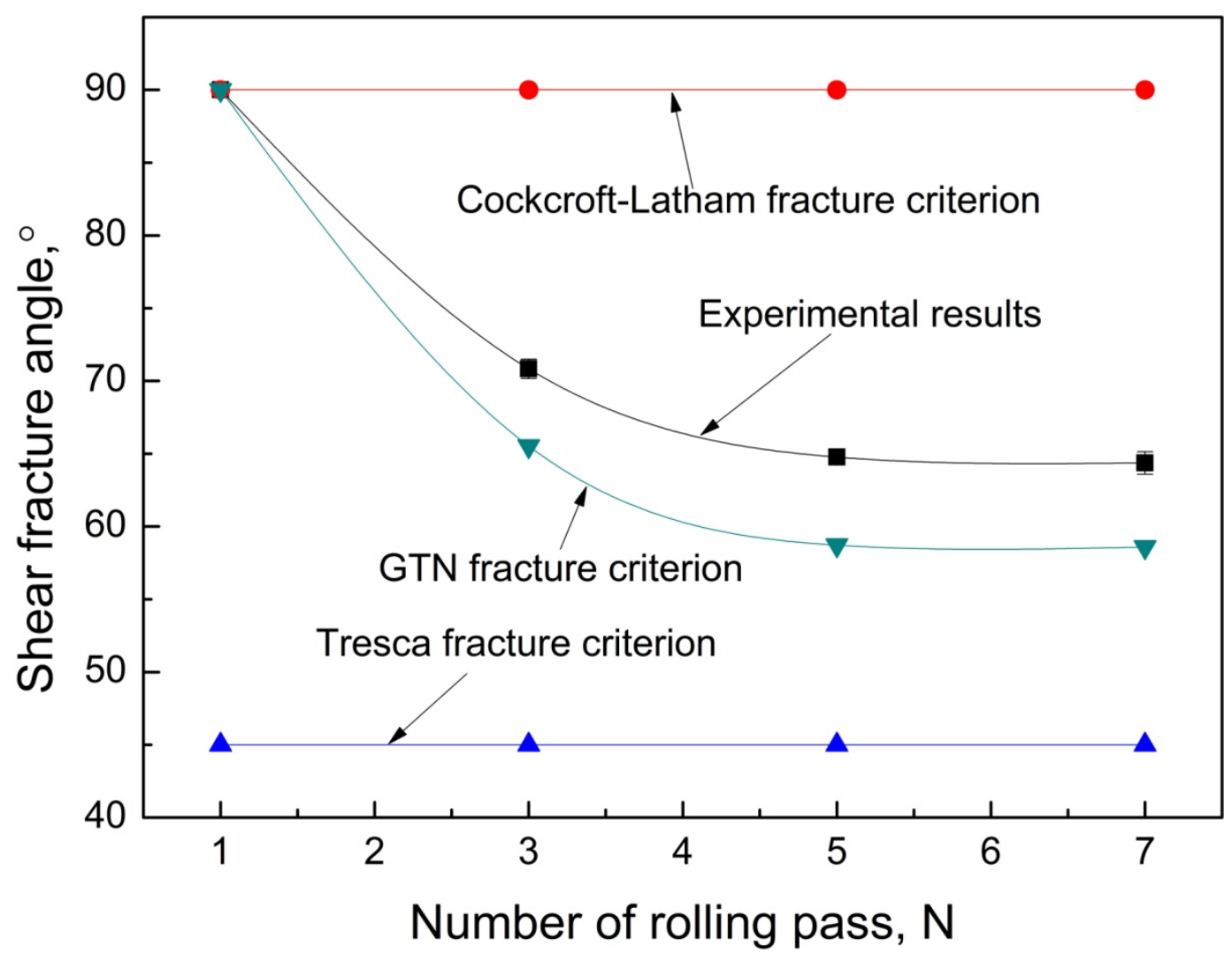

Figure 5. Shear fracture angle by simulation and experiment. 

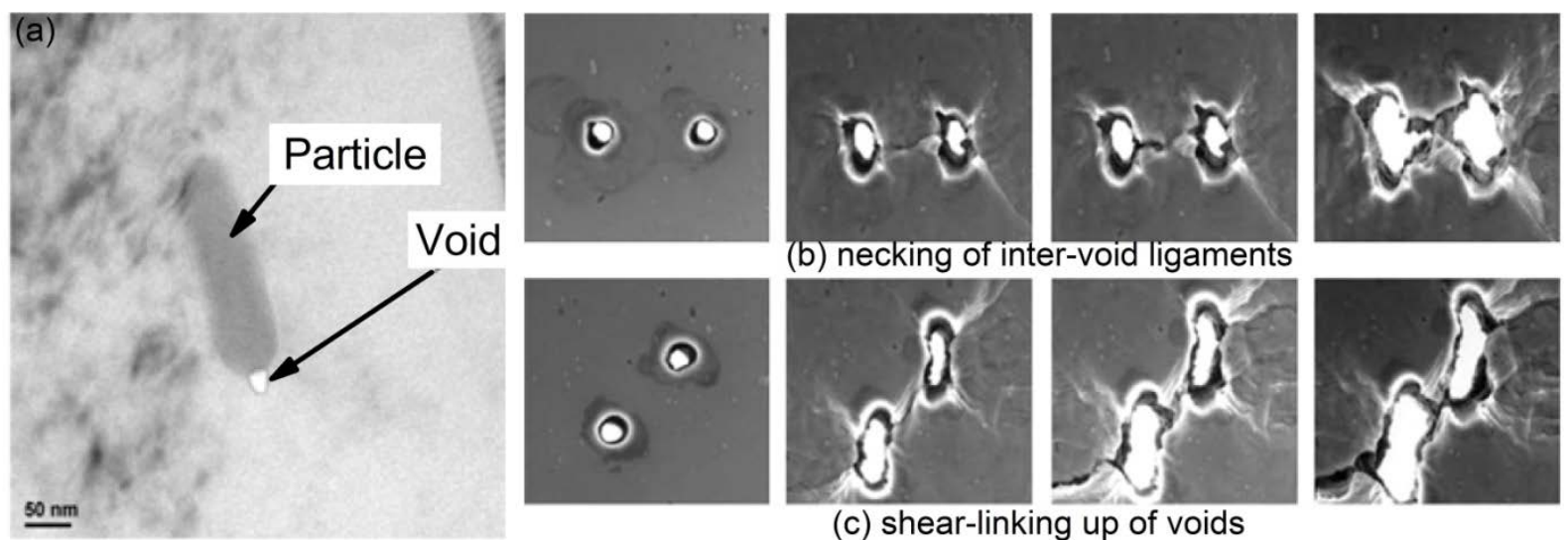

(c) shear-linking up of voids

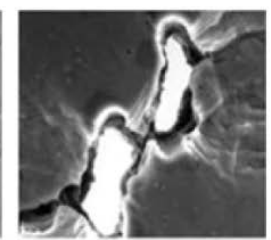

Figure 6. Fracture behavior caused by void coalescences. (a) void around particle after rolling; (b) necking of inter-void ligaments and (c) shear-linking up of voids. 

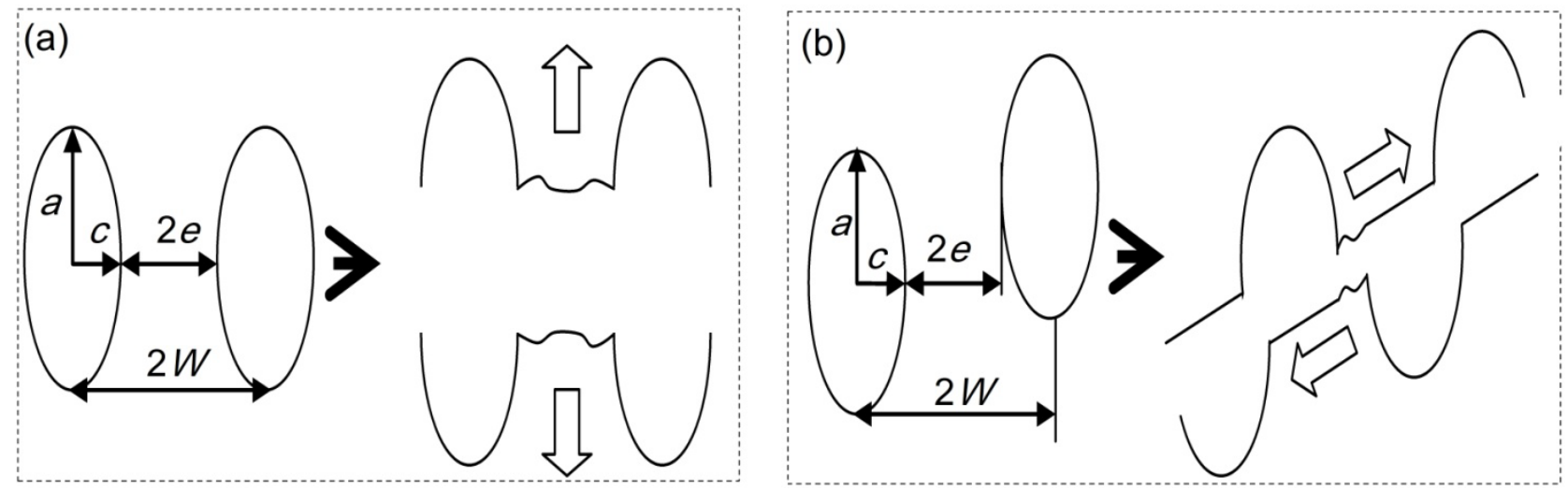

Figure 7. Illustration of void coalescence, (a) necking of inter-void ligaments, (b) shear-linking up of voids. 


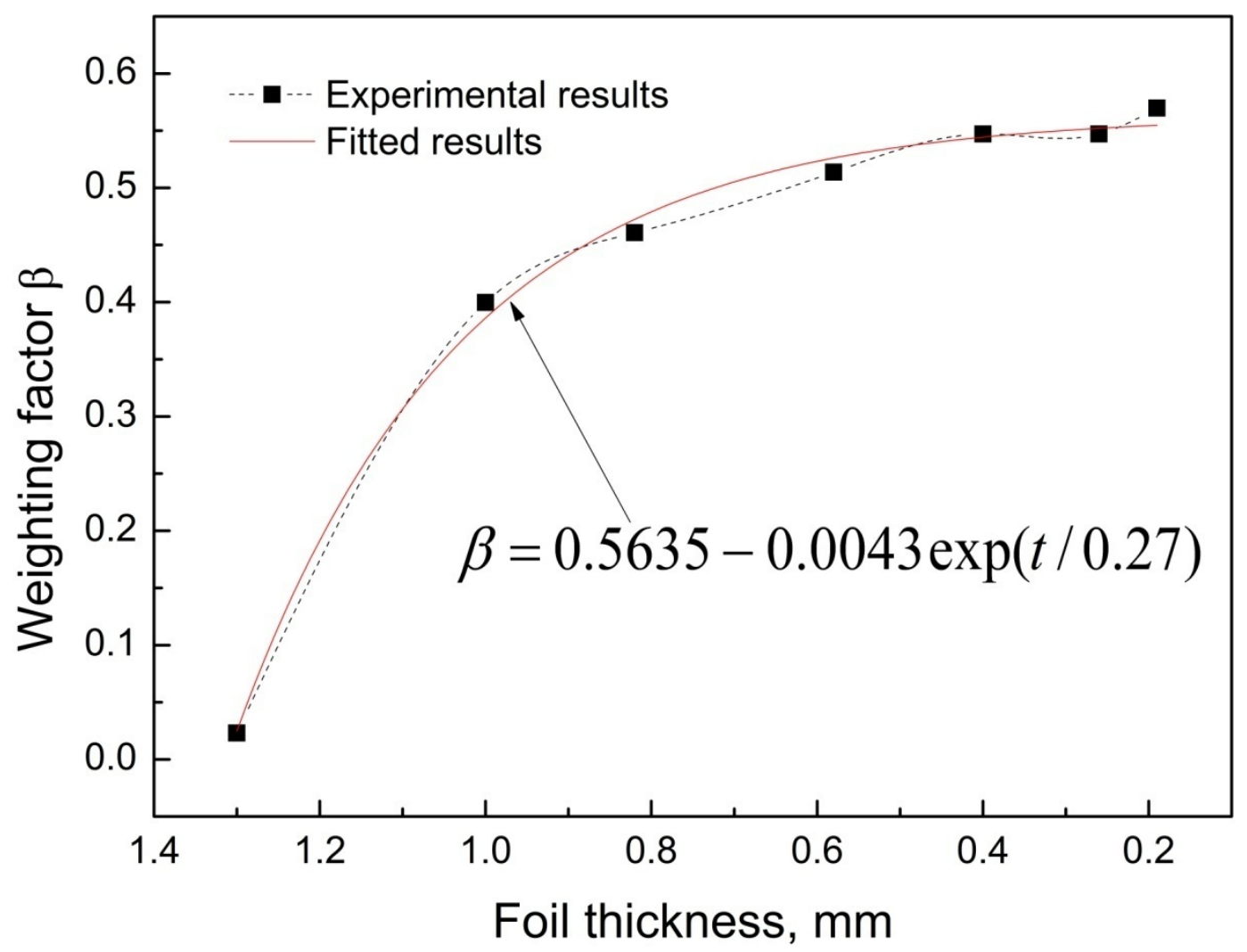

Figure 8. Weighting factor $\beta$ as a function of foil thickness. 


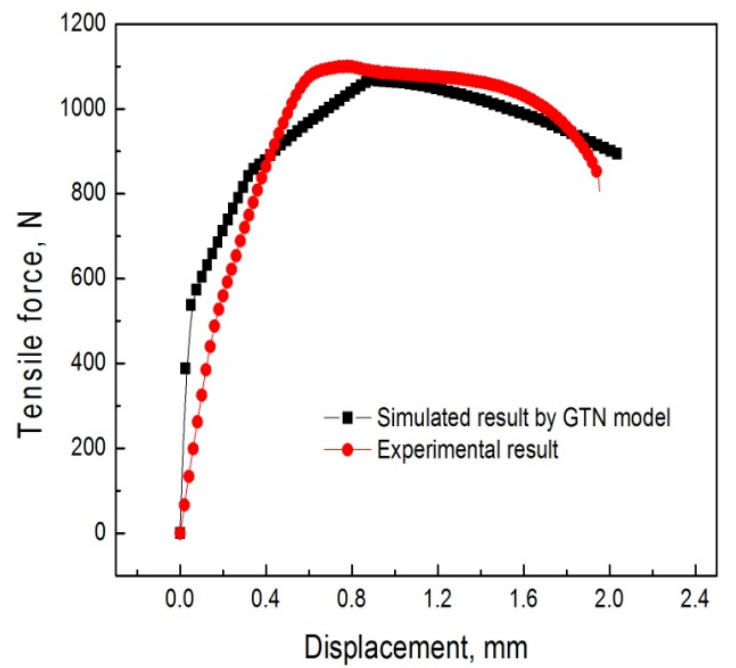

(a)

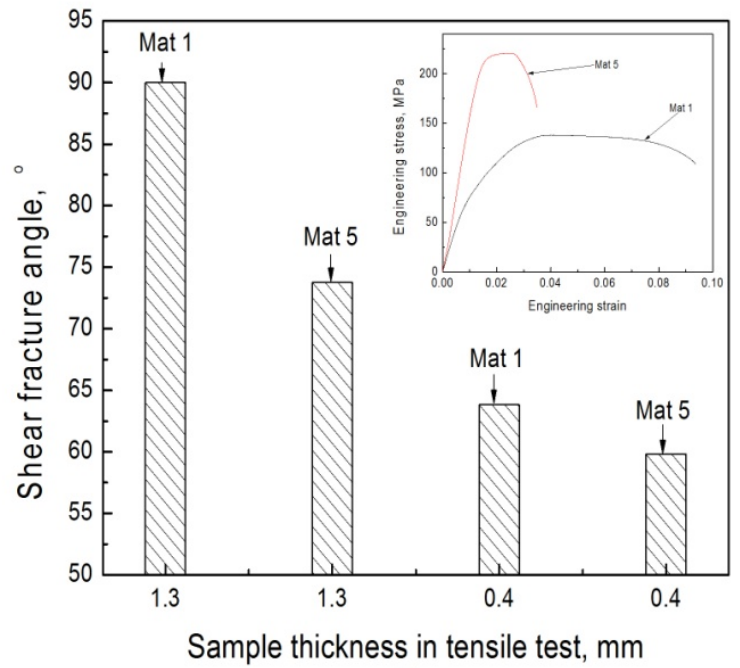

(b)

Figure 9. Tensile force vs displacement curve between simulated and experimental results for 1.3 mm thickness sample (a), and shear fracture angle with variable thicknesses and material parameters (b). 


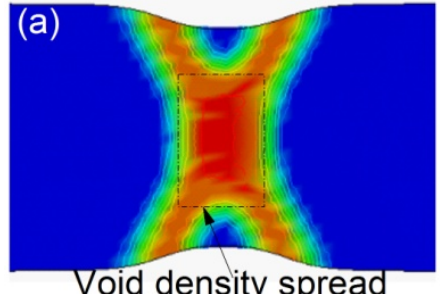

Void density spread before fracture

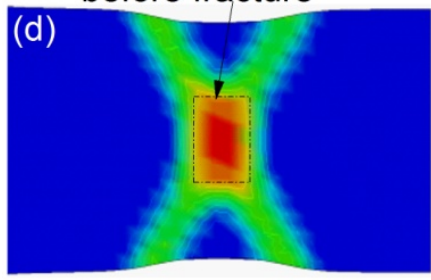

(g)

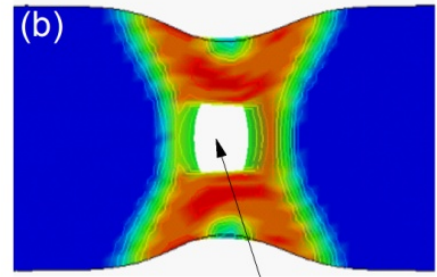

Size of initiated fracture

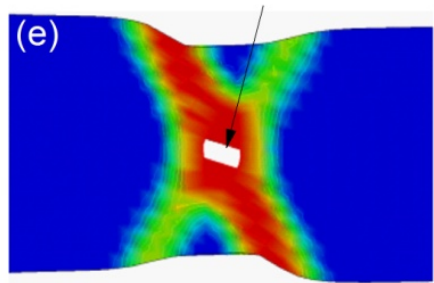

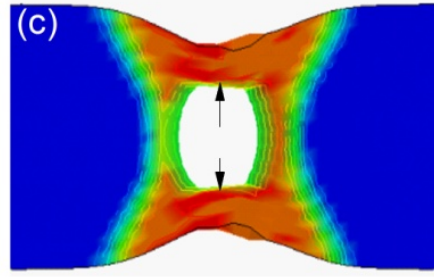

8.7

$7.8-$

$7.0-$

$6.1-$

$5.2-$

$4.3-$

3.5

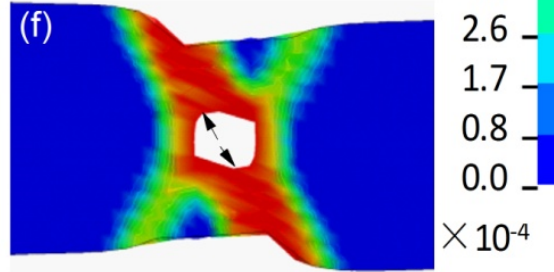

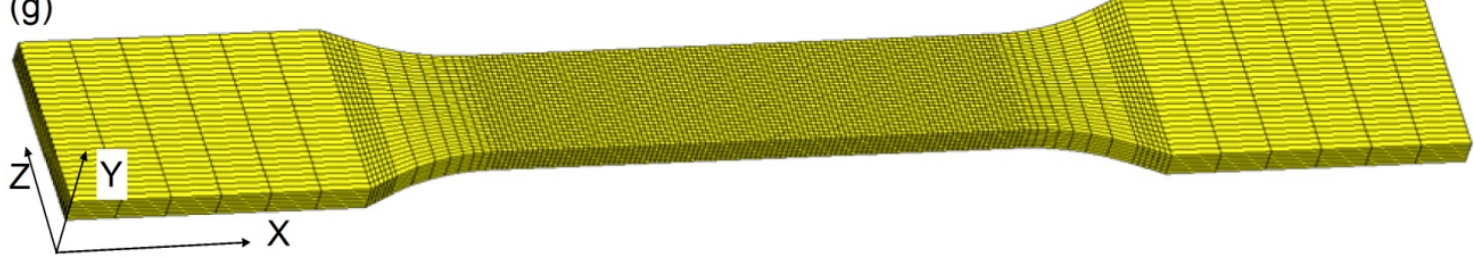

Figure 10. Void density distribution on the samples in the fracture processing for the thickness of samples $1.3 \mathrm{~mm}$, where (a), (b), and (c) for the material parameters after the first pass, (d), (e) and (f) for the material parameters after the fifth pass; (f) is the geometry and mesh of tensile samples. 


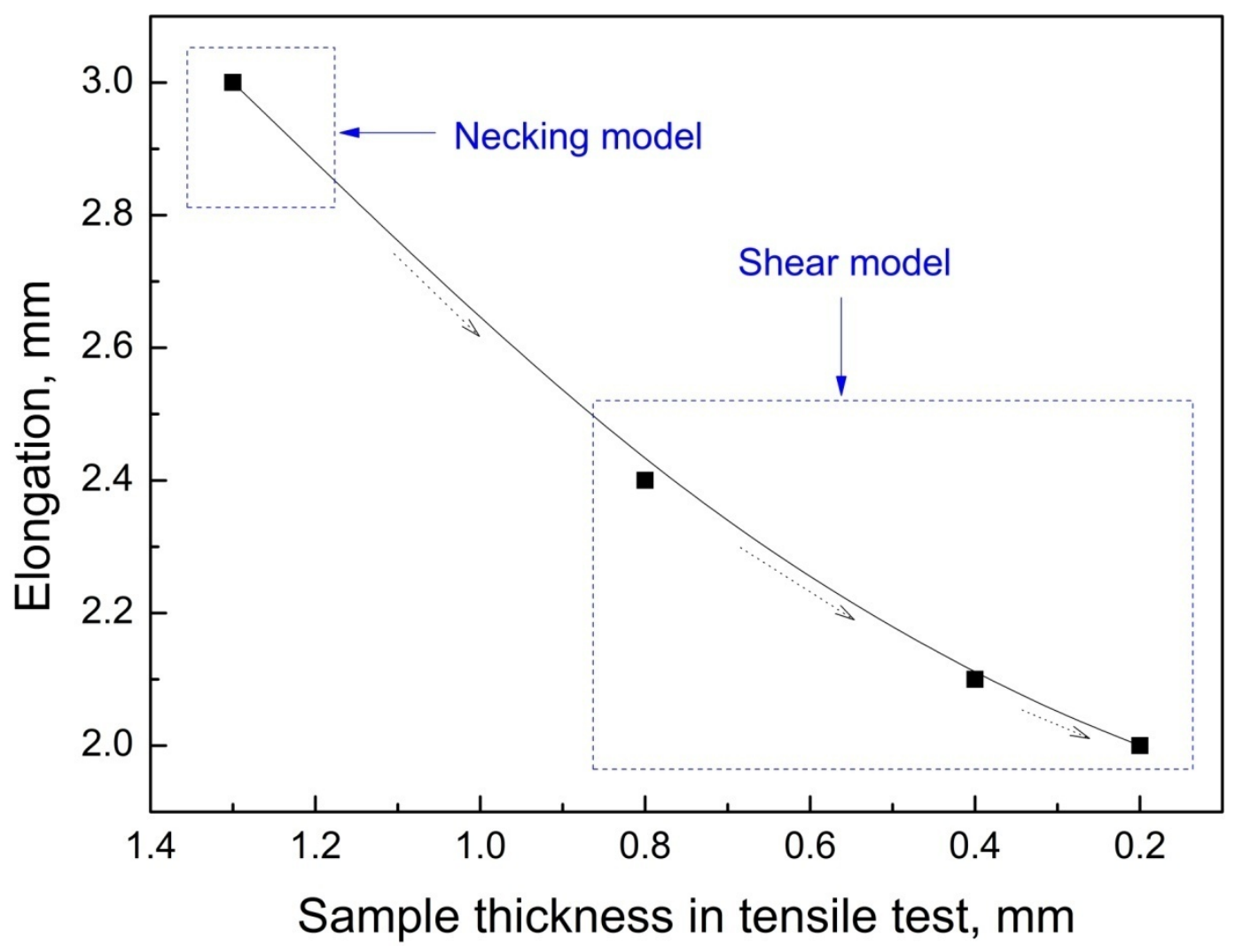

Figure 11. Elongation of samples with the same materials and variable thickness of samples. 


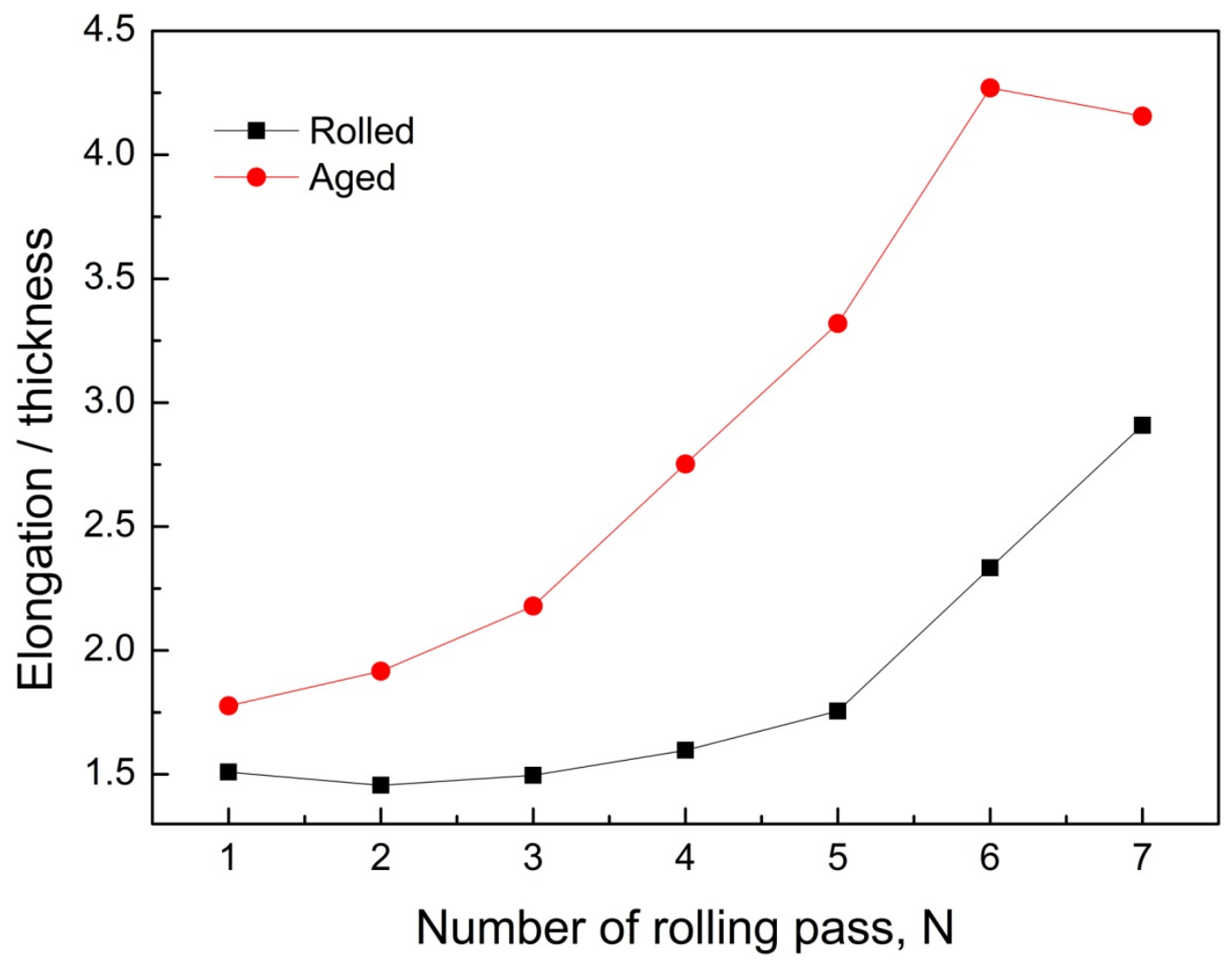

Figure 12. Change of elongation/thickness during AC rolling. 